\title{
Taiwanese Gambling Behaviors, Perceptions, and Attitudes
}

\author{
Cheng-Wei Chung ${ }^{1}$, Jiun-Jia Hsu ${ }^{2 *}$, Che Hao Chang ${ }^{3}$ \\ ${ }^{1}$ Department of Leisure, Recreation and Tourism Management, Shu-Te University, Kaohsiung County, Taiwan; ${ }^{2}$ Department of \\ Transportation Technology \& Management, Kainan University, Taoyuan, Taiwan; ${ }^{3}$ Master of Science in Hotel Administration Wil- \\ liam F. Harrah College of Hotel Administration, Graduate College University of Nevada, Las Vegas, USA. \\ Email: jhsu@mail.knu.edu.tw, alexccw@stu.edu.tw
}

Received May $8^{\text {th }}, 2012$; revised June $12^{\text {th }}, 2012$; accepted July $15^{\text {th }}, 2012$

\begin{abstract}
This study categorizes different Taiwanese gambling types using Problem Gambling Severity Index (PGSI), and further evaluates the perceptions and attitudes toward the legalization of casino gambling. A survey was conducted using convenient sampling and distributed by Internet. Results indicate that across groups of different types of gamblers, there are significant differences in perceptions toward the legalized casino gambling industry; and there are significant differences in attitudes toward legalized casino gambling. Additionally, there are significant differences between perceptions toward the legalized casino gambling industry, and attitudes toward the legalization of casino gambling. In general, non-gamblers are relatively more conservative toward the development of the casino gaming industry due to non-gamblers' sensitivity toward the involvement of the economic and social costs involved in investing in this particular industry. In addition, the results of this study provide the Taiwan government with information about Taiwanese gambling behaviors and opinions toward newly legalized gambling. By understanding Taiwan residents' gambling behaviors, perceptions, and attitudes prior to the opening of the casinos, this study could benefit Taiwan society and maximize the benefits and minimize the costs associate with the development of the casino industry.
\end{abstract}

Keywords: Casino Gambling; Problem Gambling Severity Index (PGSI); Behavior; Perception; Attitude

\section{Introduction}

According to the forecast done by the World Tourism Organization, there will be 195 million tourists visiting East Asia and the Pacific region in 2010, and the number will continue to grow to 397 million in 2020. Tourism has been an important industry in many Asian countries. Studies have already shown that the casino gambling industry stimulates tourism $[1,2]$. The successful cases of Macau and Las Vegas have attracted some Asian countries' interests. One of the current trends in many Asian countries has been to develop the casino industry to attract more visitors. Currently, Macau is the largest gaming destination in Asia, and countries such as Korea, Thailand, and the Philippines are also expanding their gaming industries.

In Taiwan, legislators proposed legalizing casino gaming as a stimulus to spur the economy as well as the tourism business [3-5]. Many casino entertainment corporations have shown strong interests in investing in Taiwan [4-6]. Taiwan is viewed as one of the best potential Asian markets for legalized gambling [5]. With the economic and international trends evolving, the Taiwan government

${ }^{*}$ Corresponding author. plans to develop tourism and the cultural and recreational industry to boost Taiwan's economy [7]. The Taiwan government eventually approved casinos to operate in the leisure resorts on the outlying islands in January, 2009. In general, gambling has been banned throughout most of Taiwan's history; excluding some government issued and managed lotteries. With social and economic changes, gambling may be viewed differently in the eyes of the Taiwan residents today [8].

The gaming industry usually brings some positive benefits to countries; however, some negative impacts have been reported [9-13]. Problem gambling is common. Some countries, such as Spain, United States, New Zealand, Swedish, and Macau, where gambling is legalized, began noticing the problems associated with prevalent gambling issues [14-16]. Also, some studies showed that ethnic Chinese tends to have a higher risk for problematic gambling. The gaming industry is relatively new to Taiwan. In order to minimize the negative social impacts of legalized casino gambling, it is important for the Taiwan government to understand resident gambling types and their attitudes toward gambling. Currently, there is not much extant research about Taiwanese gambling behaviors and their attitudes toward legal casino gambling. 
Thus, the purpose of this study is to understand Taiwanese gambling behaviors, perceptions toward gambling, and their attitudes toward legal casino gambling prior to the opening of casinos.

\section{Literature Review}

\subsection{The Current Gambling Markets in Asia}

Gaming has been in existence in Asia for centuries. In many Asian cultures, playing games is an integral part of people's lives [6]. The American Gaming Association conducted a survey that indicated that gambling revenues in Asian casinos are likely to surpass those in the United Sates by 2012 [17]. Experts in the gaming industry see Asia as a dynamic industrial marketplace with an enormous growth potential [18,19] categorized Asia gambling markets into five areas based on geographic vicinity and similar patterns of customer base and business performance in the casino industry: China, including Hong Kong and Macau; Australia; the Philippines and Malaysia; Vietnam and Cambodia; and South Korea.

\subsection{Brief Gambling History of Taiwan}

Generally speaking, gambling activities are not allowed in Taiwanese society. Gambling is perceived as being addictive, harmful to society. The peak of the flower match game was in 1896, with many citizens wallowed in gambling and unable to stop. In 1898, the government decided to strengthen the enforcement of its ban on gambling activities; people who were caught gambling would be sent to the courts. This resulted in an abundant outflow of capital to other countries [20]. In other words, the Taiwanese never stopped gambling, even when the government banned gambling activities (lotteries). The history of Taiwan's lotteries is shown in Table $\mathbf{1 .}$

\subsection{Perceptions and Attitudes toward the Legalization of Gambling}

This paper would like to explore Taiwan citizens' attitudes, no matter if they live on the mainland or outer islands, via a survey method. Despite the types of problem gambling screens used, the common finding of priorresearch is that the number of problem gamblers in- creased along with the increasing of opening or expanding legal and commercial gambling. Chen, an authoritative psychologist in Taiwan, referenced a foreign study and predicted that, according to the common issue of problem gambling, Taiwan has 460,000 problematic gamblers in the entire nation, where the population is 23 million people. [22] addressed that problem gamblers in Australia contributed to almost one-third of the gaming industry's total revenue. Some social groups even protested that the new gaming legislation would create more addictive gamblers, which would in turn waste social resources. The negative impact created by problem gamblers should be considered before any casinos opened in Taiwan.

\section{Methodology of the Study}

This study is focused on Taiwanese gambling behaviors, perceptions, and attitudes toward the legalization of casino gambling. The methodology of this study is followed:

\subsection{Hypotheses Development}

This study attempts to understand Taiwanese gambling behaviors, their perceptions toward the legalized casino gambling industry prior to the opening of casinos in Taiwan, and also to verify Taiwanese attitudes toward the legalization of casino gambling. Figure 1 illustrates the research structure mentioned above:

Several studies have surveyed the different perceptions and attitudes toward legalized casino gambling based on demographic differences, such as gender, age, social class, and ethnicity [13,23-25] but there are no studies comparing the various perceptions and attitudes toward the legalization of casino gambling among different types of gamblers. This paper has applied the PGSI to categorize different gambler types to include non-gamblers, non-problem gamblers, low-risk and moderate-risk gamblers, and problem gamblers. This study expects to understand the different opinions toward perceptions and attitudes of legalized casino gambling among these four groups of gamblers. By understanding the different groups' opinions toward the legalization of casino gamthe possible negative impact on Taiwan. Taiwan is a rare

Table 1. Historical issuance of lotteries.

\begin{tabular}{ccccc}
\hline & Patriot lottery & Charity lottery & Kaohsiung lottery & Two-in-one lottery \\
\hline Issue period & $1950-1988$ & 1990 & 1999 & $1999-2001$ \\
Issue purpose & Finance for construction & Social welfare & Social welfare & Reconstruction budget \\
Organization & Taiwan government & Taipei government & Kaohsiung government & Ministry of finance \\
\hline
\end{tabular}

Source: [21]. 


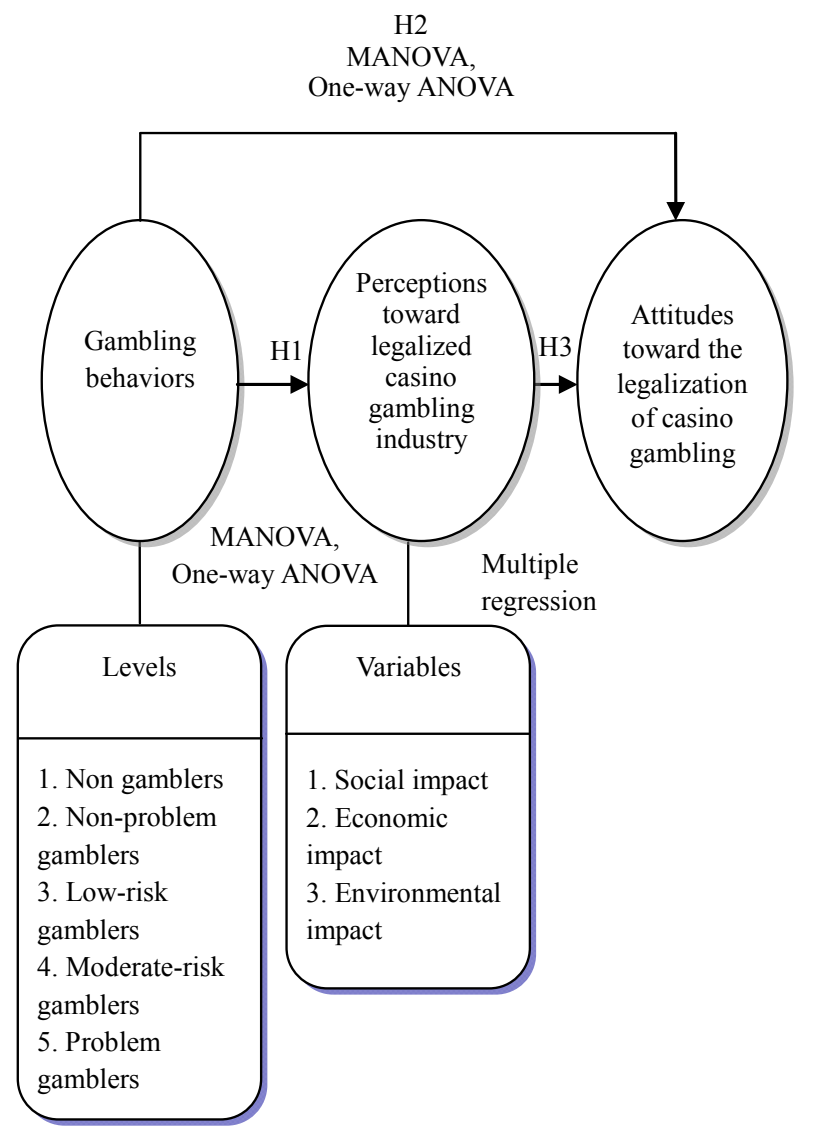

Figure 1. Research structure.

case in the world in that that would consider conducting perception and attitude research prior to opening casinos. The result could also be a reference to other countries which are keen to develop their casino industry.

The hypotheses of this study are listed as follows:

H1: Across groups of different types of gamblers, there are significant differences in perceptions toward the legalized casino gambling industry.

H2: Across groups of different types of gamblers, there are significant differences in attitudes toward the legalized casino gambling industry.

H3: There are significant differences between different perceptions toward the casino gambling industry and attitudes toward the legalization of casino gambling.

\subsection{Survey Design}

There are three main dimensions and demographic questions in the survey questionnaire, which include gambling behavior, perception of legalized gambling, and attitudes toward the legalization of casino gambling. At the end of the survey, there will be a few demographic characteristic questions.

\subsubsection{Gambling Behavior}

The study will analyze the respondents' gambling be- haviors and will assess these behaviors through various measures. Nine items of PGSI are as follows:

1) How often have you bet more than you could really afford to lose? 2) How often have you needed to gamble with larger amounts of money to get the same feeling of excitement? 3) How often have you gone back another day to try to win back the money you lost? 4) How often have you borrowed money or sold anything to get money to gamble? 5) How often have you felt that you might have a problem with gambling? 6) How often have people criticized your betting or told you that you had a gambling problem, regardless of whether or not you thought it was true? 7) How often have you felt guilty about the way you gamble, or what happens when you gamble? 8) How often has your gambling caused you any health problems, including stress or anxiety? 9) How often has your gambling caused any financial problems for you and your household?

\subsubsection{Perception of Legalized Gambling Industry}

According to the former research, three impacts are investigated in this research, including social, economic, and environmental impacts. The items in each area are listed in Table 2. In this section of the survey, the respondents will be asked 17 questions about their perceptions regarding the possible impacts created by having a legalized casino industry. A 5-point scale would be applied in the answer sheet, 1 means strongly negative, 2 means negative, 3 means neutral, 4 means positive and 5 means strongly positive.

\subsubsection{Attitudes toward the Legalization of Casino Gambling}

Some studies have already investigated Taiwanese and Penghu residents' attitudes toward the legalizations of casinos. Most studies were conducted prior to 2004. One of the core purposes of this study is to reinvestigate Taiwanese attitudes toward this new policy. The respondents will be asked 4 questions and express their attitudes toward the policy and their personal will to participate in gambling entertainment. This part of the survey used a 5

Table 2. Items assessing the legalization of casino gambling's impact.

\begin{tabular}{cc}
\hline $\begin{array}{c}\text { The variances of } \\
\text { perspective of legalized } \\
\text { casino gambling }\end{array}$ & Factors \\
\hline Social impacts & $\begin{array}{r}\text { Gambling addiction/Crime rate/Bankruptcy } \\
\text { rate/Family relation/Prostitution/Education } \\
\text { system/Life quality }\end{array}$ \\
& $\begin{array}{r}\text { Nation's reputation/Public welfare/Tourism } \\
\text { revenue/Non-gaming business } \\
\text { activities/Government tax }\end{array}$ \\
Economic impacts & income/Employment rate/Volume of visitors \\
& Natural environnent/Culture/Pollution \\
\hline
\end{tabular}


point Likert scale. Each scale has a minimum of 1 point (Strongly disagree) and a maximum of 5 points (Strongly agree), and 3 points means Neutral. Finally, the last part of the survey assesses the participants' demographic information, including gender, age, marriage status, education level, occupation, location of residency, monthly income, and religious beliefs.

\subsection{Sampling}

In order to minimize the bias and make participants feel comfortable when answering the survey questions, this survey conducts a Web Survey in Chinese rather than a face-to-face interview or telephone interview. On the other hand, in order to encourage respondents to answer honestly and make them feel comfortable when answering the PGSI questions, anonymity. The sample population will be selected using the convenience sampling method. Advertisements of the study and a Web link to the questionnaire will be posted on several popular Bulletin Board Systems and gambling related discussion Websites in order to collect diverse samples. There are many popular Bulletin Board System (BBS) in Taiwan, where everyone exchanges information. The average usage rate of BBS in Taiwan is estimated to be 100,000 users per day. Based on the current referendum policy, Taiwanese citizens who are at least 18 years of age and have a right to vote in referenda will be invited to answer the questionnaire through advertisements. Those who are younger than 18 years of age will be excluded in this study.

\subsection{Data Collection}

This study categorized all respondents into five gambling types, including non-gamblers, non-problem gamblers, low-risk and moderate-risk gamblers, and problem gamblers by using the PGSI. The questionnaire was designed based on prior research, and distributed via the Internet. Respondents were recruited by the Bulletin Board Systems and gambling related discussion Websites. A pretest was conducted from 2-5 June 2009. The results showed some gambling behaviors occurred at lottery stalls, so a choice of lottery stalls was added in the second question in the behavior section. A formal Websurvey was distributed from 5-15 June 2009. The total number of surveys collected was 877. After filtering out surveys with missing data, 722 survey questionnaires were considered valid. The frequency and percentage of each gambler type is shown in Table 3.

\section{Finding and Analysis}

One of the main purposes of this study is to understand the perceptions of legalized casino gambling and the attitudes toward the legalization of casino gambling across four different gambler types. This chapter exhibits the survey findings from 722 respondents who complete the online survey. Moreover, this chapter examines the three hypotheses regarding current gambling behavior and opinions about legalization. The first section presents the description of the sample characteristics; the second section describes the overall survey results. Finally, the three hypotheses are tested in the last section.

\subsection{Respondents' Profiles}

A total of 877 responses were collected over a two-week period from 4-17 June 2009. The distribution of the test sampling was mainly contributed by females, $54.8 \%$, while the 18 - 27 years-of-age bracket represented $55.2 \%$. $82.7 \%$ of the sample was single. $65.7 \%$ of the sampling was college/university educated. The many on the sample work for the service industry. Most of the samples live in the North, $38.9 \%$, which contributed to $28.3 \%$ of the total sample. The survey also shows that $52.4 \%$ of the sample had no religious beliefs.

\section{1) Gambling Behavior}

There were 12 questions designed to understand and categorize the respondents' gambling behaviors and types. The result of the questions are analyzed and discussed as follows: The first step is to categorize the respondents into gamblers or non-gamblers, if the respondent answers "Yes" (1), indicating that he/she is a gambler, they are introduced to the next 11 questions; if the respondent answer "No" (2), indicating that he/she is a non-gambler, the system takes the respondents to the demographic characteristics questions. Of the total 722 respondents, $65.1 \%$ (470 out of 722 ) have participated in some kind of gambling activities with actual money in the past 12 months; $34.9 \%$ of the respondents have no gambling experience with actual money in the past 12 months and are defined as non-gamblers in this study.

The second question asked the respondents the kind of games they have gambled in the past 12 months and also tried to help respondents recall their gambling experience in the past 12 months. The question was designed as a multiple response question, which means the respondents could choose more than one answer. Of the total 470

Table 3. Sampling distribution chart.

\begin{tabular}{ccc}
\hline Gambler type & Frequency & Percent \\
\hline Non-gambler & 252 & $34.9 \%$ \\
Non-problem gambler & 154 & $21.3 \%$ \\
Low risk gambler & 149 & $20.6 \%$ \\
Moderate gambler & 123 & $17.0 \%$ \\
Problem gambler & 44 & $6.1 \%$ \\
Total & 722 & $100 \%$ \\
\hline
\end{tabular}


respondents who have gambled with actual money in the past 12 months. Table 4 shows frequencies of the games that the respondents have participated in the past 12 months.

Question 3 was designed as a multiple response question; the respondents were allowed to choose more than one answer. The purpose of this question is to understand which venues the respondents who have gambled in the past 12 months have visited. The frequency of each venue is shown in Table 5.

According to answers to questions 2 and 3, the most common gambling behaviors for the participants were to purchase lottery tickets and playing mahjong and poker. The venues of the gambling often take place at the lottery stall, participants' own homes, or at their friends/relatives' houses. [26] discussed the popularity of lottery stalls coupled with the over-marketing of the lottery games by the media in Taiwan might have brought unnecessary negative impacts on Taiwanese society as a whole. In addition, both playing mahjong and poker are the two most common leisure activities for Taiwanese.

Table 4. Gaming types and participation rate distribution chart.

\begin{tabular}{cccc}
\hline & \multicolumn{2}{c}{ Responses } & Percentage \\
\cline { 2 - 3 } & Number & Percent (\%) & of cases (\%) \\
\hline Ma Jiang & 266 & 27.7 & 56.6 \\
Lottery & 327 & 37.1 & 69.6 \\
Dice & 64 & 6.7 & 13.6 \\
Mark six & 16 & 1.7 & 3.4 \\
Sports lottery & 53 & 5.5 & 11.3 \\
$\quad$ Poker & 207 & 21.6 & 44.0 \\
Others (slot machines, roulette, & & & \\
Chinese chess, or lottery scratch & 27 & 2.8 & 5.7 \\
ticket games, etc.) & & & \\
Total & 960 & 100 & 204.3 \\
\hline
\end{tabular}

Table 5. Gambling venue and participation distribution chart.

\begin{tabular}{cccc}
\hline & \multicolumn{2}{c}{ Responses } & $\begin{array}{c}\text { Percentage of } \\
\text { cases (\%) }\end{array}$ \\
\cline { 2 - 3 } & Number Percent (\%) & 82.3 \\
\hline $\begin{array}{c}\text { At home or at friends'/relatives' } \\
\text { places }\end{array}$ & 387 & 44.7 & 4.7 \\
Underground casinos & 22 & 2.5 & 72.6 \\
Lottery stall & 341 & 39.4 & 10.2 \\
Las Vegas & 48 & 5.5 & 7.7 \\
$\quad$ Macau & 36 & 4.2 & 1.9 \\
Korea & 9 & 1.0 & \\
$\begin{array}{c}\text { Others (Vietnam, Malaysia, New } \\
\text { York, Australia, Seattle, Atlantic } \\
\text { City, gambled online, or at the } \\
\text { dorm) }\end{array}$ & 22 & 2.5 & 4.7 \\
Total & & & \\
\hline
\end{tabular}

\subsection{Survey Results}

1) Perceptions toward the Legalized Casino Gambling Industry

This dimension consisted of the social, economic, and environmental impacts, with 17 questions in total. A reliability analysis was conducted to see the internal consistency of these items. That the reliability level of each construct should exceed the critical value of 0.7 . The aggregated dimension of perception had a Cronbach reliability score of 0.852 , which means the results of the survey were highly reliable. The Cronbach's $\alpha$ of the social, economic, and environmental sections were 0.780 , 0.812 , and 0.632 respectively, which mean the reliabilities were all acceptable.

2) Social Impact

In the social impact section of the assessed survey, the respondents' perception toward the legalized casino gambling industry on seven different aspects, which included gambling addiction, crime rate, bankruptcy rate, family relationship, prostitution, education level, and life quality. In this section, the respondents considered that the legalized casino industry will affect the social aspect negatively in general (mean $=-0.511$ ). In those seven questions, the crime rate receives the lowest negative value, which has a mean score of -0.658 . Of the total respondents, $65.5 \%$ were concerned that the legalized casino industry will lead an increase of the crime rate, followed by the family relationship, which is also expected to be affected adversely, with a mean score of -0.626 . Of the total respondents, $61.3 \%$ agreed that the legalized casino industry will pose a threat on family relationships. Prostitution is also an area of concern, with a mean score of -0.613 . Of the total respondents, $59.3 \%$ were concerned with issues related to prostitution resulting from the legalization of casino gambling. The mean score of various factors are summarized in Table 6 below.

Table 6. Respondents' perceptions toward social impact.

How will the legalized casino industry affect the following aspects of life in Taiwan? (Strongly negative impact $(-2)$, Strongly positive impact $(+2))$

\begin{tabular}{cc} 
impact $(+2))$ & Mean \\
\hline Social impact & -0.493 \\
Gambling addiction & -0.658 \\
Crime rate & -0.551 \\
Bankruptcy rate & -0.626 \\
Family relationship & -0.614 \\
Prostitution & -0.413 \\
Education level & -0.224 \\
Life quality & -0.257 \\
Overall &
\end{tabular}




\section{3) Economic Impact}

The economic aspect consists of public welfare, Taiwan's reputation, tourism revenue, non-gaming business, government tax income, employment rate, and the volume of visitors. For these 7 questions, using a 5-point scale, $(2=$ strongly positive, $-2=$ strong negative $)$, the mean score is 0.885 , which indicates that overall, the respondents showed positive attitudes toward legalized casino gambling impact on the economy.

Table 7 illustrates that the legalized casino industry will bring positive benefits to Taiwan's economy. Of those seven factors, tourism revenue has the highest mean score of 1.223 , which means respondents expect the legalized casino industry to benefit tourism revenue. Among the total respondents, the majority agree that the legalized casino industry will affect tourism revenue favorably, in which $89.2 \%$ of the total respondents indicated the legalized casino industry will positively or strongly positively benefit tourism revenue. The total respondents answered that the legalized casino industry will help increase the volume of visitors to Taiwan, with the mean score of $1.114 \%, 54.4 \%$, and $30.5 \%$ say that the legalized casino industry will strongly benefit the volume of visitors. The factor which has the third highest mean score is the government tax income, with a mean score of 1.107. A majority of the respondents $(83.6 \%)$ showed a convinced attitude toward the benefits brought by legalized casino gambling, $51.2 \%$ of the total responses answered positive impacts, and $32.4 \%$ answered strongly positive.

4) Environmental Impact

The economic aspect is comprised of three sub-aspects: natural environment, culture, and pollution. A 5-point scale was applied to these three questions, $(2=$ strongly positive, $-2=$ strong negative). Table 8 shows that the mean score of the overall environmental impact is -0.410 , which indicates that overall, the respondents show negative attitudes toward the affects of legalized casino gambling on the environment. Moreover, pollution has a mean score of -0.501 , which has the lowest negative value compared to another two aspects. Among the total respondents, more than half think that the legalized casino industry will negatively impact pollution (13.3\% negative impact, $42.1 \%$ strongly negative impact). Another sub-aspect is the natural environment which has a mean score of -0.493 , in which $53.7 \%$ of the respondents think that the legalized casino industry will affect the natural environment for the worse $(13.9 \%$ strongly negative, $39.8 \%$ negative). Regarding the cultural aspect, the mean score is -0.234 , which means that the legalized casino industry will negatively affect the culture; of the total respondents, $36.1 \%$ answered negative impact and $8.7 \%$ answered strongly negative.

5) Summary of Perception Results
Table 7. Respondents' perceptions toward economic impacts.

\begin{tabular}{ll}
\hline $\begin{array}{l}\text { How will the legalized casino industry affect the following aspects of } \\
\text { life in Taiwan? (Strongly negative impact }(-2) \text {, Strongly positive } \\
\text { impact (+2)) }\end{array}$ \\
\hline Economic impact & Mean \\
Public welfare & 0.490 \\
Reputation of Taiwan & 0.780 \\
Tourism revenue & 1.223 \\
Non-gaming business activities & 0.568 \\
Government tax income & 1.107 \\
Employment rate & 0.913 \\
Volume of visitors & 1.114 \\
Overall & 0.885 \\
\hline
\end{tabular}

Table 8. Respondents' perceptions toward environmental impact.

How will legalized casino industry affect the following aspects of life in Taiwan? (Strongly negative impact $(-2)$, Strongly positive impact (+2))

$\begin{array}{cc}\text { Environmental impact } & \text { Mean } \\ \text { Natural environment } & -0.493 \\ \text { Culture } & -0.234 \\ \text { Pollution } & -0.501 \\ \text { Overall } & -0.410\end{array}$

The respondents' perceptions of the legalized casino industry are positive only in its economic impact with a mean score of 0.885 . The respondents think that the legalized casino industry could benefit Taiwan and the top three positive factors are tourism revenue, volume of visitors, and government tax income. Overall, the total respondents expect the legalized casino industry will negatively impact Taiwan both environmentally and socially. The top three negative factors in the perception dimension are crime rate, family relationships, and prostitution. Participants believe that the casinos were able to stimulate the economy and have a positive impact on job creation. The result of the study and the characteristics of the samples matched, and this study will be discussed in detail in the following sections regarding the different attitudes among various gambling types.

6) The Attitude toward the Legalization of Casino Gambling

This dimension consisted of 6 questions, using a 5 -point scale with 1 meaning "Strongly Disagree" and 5 meaning "Strongly Agree," and was applied to those 4 items. The overall attitude dimension has a high reliability with a Cronbach's $\alpha$ score of 0.899 , which indicated the reliability was acceptable. Table 9 presents the central tendency of the 4 questions of the attitude dimension.

Question 3, I would like to visit gambling destinations 
Table 9. Attitudes toward casino gambling.

The attitudes toward the legalization of casino gambling $($ Strongly agree $=5$, Strongly disagree $=1)$

\begin{tabular}{cc} 
Attitude (5 = Strongly agree, 1 = Strongly disagree) & Mean \\
I support the legalization of casino gambling & 3.270 \\
I would gamble at legal casinos in Taiwan & 3.080 \\
$\begin{array}{c}\text { I would like to visit gambling destinations in Taiwan } \\
\text { verall, I think that benefits from legalized casinos would } \\
\text { outweigh the costs }\end{array}$ & 3.386 \\
\hline
\end{tabular}

in Taiwan, has a mean score of 3.386. Of the total respondents, $37.3 \%$ agreed and $17.6 \%$ strongly agreed that he/she would like to visit a gambling destination in Taiwan. Only $23.2 \%$ disagreed or strongly disagreed with Question 3. Question 1 has a mean score of 3.270. Of the total respondents, less than half of the respondents, $34.2 \%$, agreed and $12.3 \%$ strongly agreed with the legalization of casino gambling, with $30.1 \%$ having neutral attitudes toward the legalization. [5] conducted a survey by using convenience sampling; within the total valid responses, $24.5 \%$ never heard about the legalization of casino gambling, which means there are still Taiwanese who are unfamiliar with the new legalization. This could be a reason why $30.1 \%$ answered neutral on this question. Question 4 has a mean score of 3.173 with $29.5 \%$ agreeing, $14.0 \%$ strongly agreeing, $17.2 \%$ disagreeing, and 11.5 strongly disagreeing that the benefits of the legalized casino industry would overweigh costs. Question 2 has a mean score of 3.080 , with $14.1 \%$ strongly agreeing, $28.4 \%$ agreeing, $25.5 \%$ neutral, $15.4 \%$ disagreeing, and $16.6 \%$ strongly disagreeing with that he/she would gamble at legalized casinos in Taiwan.

This study further compares the different mean scores among various ethnic characteristics and attitudes. The results show that a positive attitude exists in the minds of different ethnics. With the exception of married couples, married with child/children, housekeepers, and retirees; these groups lead a relatively stable life and thus are concerned with the potential negative impacts [5]. Hypothesis 2 will be further discussed along with the different attitudes among various gamblers and their attitudes toward the development of the gaming industry.

\subsection{Hypothesis Testing}

Hypothesis 1: Across groups of different types of gamblers, there are significant differences in perceptions toward the legalized casino gambling industry.

With regard to the testing of Hypothesis 1, MANOVA, a One-way ANOVA and Duncan Post Hoc Test were conducted to examine the relationships between types of gamblers and their perceptions toward legalized casino gambling in three aspects including 17 items. First of all, this research applied the multivariate analysis of variance
(MANOVA) to test the differences in the perceptions of legalized casino gambling across four different groups, including non-gamblers, non-problem gamblers, low-risk and moderate gamblers, and problem gamblers. If the score of Wilk's $\Lambda$ is lower than 0.05 , it means that there are significant differences in the perception dimension across these 5 groups. As shown in Table 10, the multivariate analysis of variance was compiled to determine if there are significant differences in perceptions among various gambling behaviors. Scores for all five groups were analyzed simultaneously. The Duncan finding again showed that the mean scores of low-risk or moderate-risk gamblers $(-0.386)$, low and problem gamblers $(-0.442)$ were significantly higher than non-gamblers $(-0.640)$ in the variable of social impact. Regarding the economic impact, the mean scores of the low-risk and moderaterisk gamblers (1.014), problem gamblers (0.974), and non-problem gamblers $(0.917)$ were significantly higher than non-gamblers $(0.710)$. There were also significantly dissimilar results in the variable of environmental impact; the mean scores of the problem gamblers $(-0.212)$, lowrisk and moderate-risk gamblers $(-0.240)$ were considerably higher than non-problem gamblers $(-0.470)$ and non-gamblers $(-0.590)$.

Thus, the results of the MANOVA, one-way ANOVA, and the Duncan Test have clearly supported Hypothesis 1.

Hypothesis 2: Across groups of different types of gamblers, there are significant differences in attitudes toward the legalized casino gambling industry.

As shown in Table 11, in the beginning, the multivariate analysis of variance was conducted to determine if there are significant differences in attitudes among assorted gambling behaviors. Scores for all five groups were analyzed simultaneously. The MANOVA with Wilk's $\Lambda$ set at 0.05 indicated that there are significant differences for all five types of gambling behaviors taken together. The resulting $\mathrm{F}$ ratio of 8.912 was found to be significant at the 0.000 level with a value lower than 0.05 to show that there are significant differences in attitudes among the five groups. To determine which variable dif-

Table 10. The results of MANOVA and the one-way ANOVA for Hypothesis 1.

\begin{tabular}{|c|c|c|c|c|c|}
\hline \multicolumn{5}{|c|}{ Gambler type } & \multirow{3}{*}{$\begin{array}{l}\text { Duncan post } \\
\text { hoc test }\end{array}$} \\
\hline & \multicolumn{2}{|c|}{ Wilk's $\Lambda$ test } & \multicolumn{2}{|c|}{ One-way ANOVA } & \\
\hline & F-value & P-value & F-value & $\mathrm{P}$-value & \\
\hline Social & & & 6.360 & 0.000 & $3,4>1$ \\
\hline Economic & 6.166 & 0.000 & 13.106 & 0.000 & $3,4,2>1$ \\
\hline Environmental & & & 11.054 & 0.000 & $4,3>2,1$ \\
\hline
\end{tabular}

$1=$ Non-gambler, 2 = Non-problem gambler, $3=$ Low risk and moderate gambler, 4 = Problem gambler. 
ferences were statistically significant in the attitude dimension, ANOVA and the Duncan Post Hoc Test were conducted. The ANOVA test found that statistically significance in all four variables. The Duncan Post Hoc Test was than conducted to further explain the levels of differences among those four groups, see Table 12.

1) "I support the legalization of casino gambling":

In this variable, the Duncan finding again showed that the mean scores of problem gamblers (3.363) and lowrisk and moderate-risk gamblers (3.592) were significantly higher than non-problem gamblers; the mean score of non-problem gamblers (3.247) was higher than nongamblers (2.873).

2) "I would gamble at legal casinos in Taiwan":

In this variable, the Duncan finding again showed that the mean scores of the problem gamblers (3.636), lowrisk, and moderate-risk gamblers (3.496) were significantly higher than non-problem gamblers (3.078) and non-gamblers (2.536); and non-problem gamblers (3.078) were significantly higher than non-gamblers (2.536).

3) "I would like to visit gambling destinations in Taiwan":

In this variable, the Duncan finding again showed that the mean scores of problem gamblers (3.864), low-risk and moderate-risk gamblers (3.765) were significantly higher than non-problem gamblers (3.422) and nongamblers (2.873); and non-problem gamblers (3.422) were significantly higher than non-gamblers (2.873).

4) "Overall, I think that benefits from legalized casinos

Table 11. Mean scores of each group's perception of the impact of gambling.

\begin{tabular}{cccc}
\hline Type & Social & Economic & Environmental \\
\hline Non-gambler (1) & -0.640 & 0.710 & -0.590 \\
Non-problem gambler (2) & -0.542 & 0.917 & -0.470 \\
$\begin{array}{c}\text { Low/Moderate risk } \\
\text { gambler (3) }\end{array}$ & -0.386 & 1.104 & -0.240 \\
Problem gambler (4) & -0.442 & 0.970 & -0.212 \\
\hline
\end{tabular}

Table 12. The result of MANOVA and the one-way ANOVA for Hypothesis 1.

\begin{tabular}{|c|c|c|c|c|c|}
\hline \multirow{3}{*}{ Attitudes } & \multicolumn{4}{|c|}{ Gambler type } & \multirow{3}{*}{$\begin{array}{c}\text { Duncan post } \\
\text { hoc test }\end{array}$} \\
\hline & \multicolumn{2}{|c|}{ Wilk's $\Lambda$ Test } & \multicolumn{2}{|c|}{ One-way ANOVA } & \\
\hline & F-value & P-value & F-value & P-value & \\
\hline The legalization & & & 21.346 & 0.000 & $4,3>2>1$ \\
\hline Gamble & & & 30.463 & 0.000 & $4,3>2>1$ \\
\hline Visit & 0.912 & 0.000 & 29.064 & 0.000 & $4,3>2>1$ \\
\hline Benefits $>$ Costs & & & 16.264 & 0.000 & $4,3,2>1$ \\
\hline
\end{tabular}

1 = Non-gambler, 2 = Non-problem gambler, 3 = Low risk and Moderate risk gambler, $4=$ Problem gambler. would outweigh the costs":

In this variable, the Duncan finding again showed that the mean scores of problem gamblers (3.500), low-risk and moderate gamblers (3.467) and non-problem gamblers (3.201) were significantly higher than non-gamblers (2.782).

Thus, the results of MANOVA, one-way ANOVA, and the Duncan Test support Hypothesis 2. [11] surveyed a total of 453 residents from Penghu and Taipei. Ho's study compared the different attitudes toward the legalization of casino gambling by different demographic characteristics. The results showed that males, people who have casino gambling experiences, and residents who were aware of the legalization were more positive about the legalizetion of casino gambling. Nevertheless, according to the results of Hypothesis 3, this study further explains that non-gamblers were conservative on the participation or supporting of the legislatures, with fairly negative perceptions, while gamblers have more positive attitudes. Furthermore, high-risk gamblers are more willing to support the relating legislation, and were willing to participate in the gambling activities. Overall, the aggregate belief was that the positive benefits would outweigh the costs. [24] have mentioned the willingness of participation in gambling behaviors, for example, people who have visited casino destinations or perceive benefits from gambling had more positive perceptions toward gambling; the results match the finding of this study.

Hypothesis 3: There are significant differences between different perceptions toward the casino gambling industry and attitudes toward the legalization of casino gambling.

Multiple regression is a statistical method conducted to establish the relationship between independent (predictor) variables and dependent variables. Multiple regression establishes the effectiveness of a set of independent variables in explaining a proportion of variance in a dependent variable through a significance test of R2. By comparing the beta weights, multiple regression determines which independent variables are the strongest predictors of the dependent variables. In general, multiple regression is performed to answer questions, such as "How well a set of variables is able to predict a particular outcome", "Which variable is the best predictor of an outcome", and "Is a particular predictor variable still able to predict an outcome when the effects of another variable are controlled for". In this study, the independent variables are $\mathrm{X} 1=$ social impact, $\mathrm{X} 2=$ economic impact, and X3 = environmental impact; and dependent variables $(\mathrm{Y})=$ attitude toward the legalization of casino gambling. The results are presented as follows: Regression model: The attitude toward the legalization of casino gambling

The result of Model 1 is showed in Table 13. The formula of the multiple regression model is stated as: 
Table 13. The result of multiple regression of the attitude toward the legalization of casino gambling.

\begin{tabular}{|c|c|c|c|c|c|c|c|c|c|c|c|c|}
\hline & \multicolumn{2}{|c|}{$\begin{array}{l}\text { Unstandardized } \\
\text { Coefficients }\end{array}$} & \multirow{2}{*}{$\begin{array}{c}\text { Standardized } \\
\text { Coefficients }\end{array}$} & \multirow[t]{2}{*}{$\mathrm{t}$} & \multirow[t]{2}{*}{ Sig. } & \multicolumn{2}{|c|}{$\begin{array}{l}\text { Co-linearity } \\
\text { statistics }\end{array}$} & \multirow{2}{*}{$\mathrm{R}$} & \multirow{2}{*}{$\mathrm{R}^{2}$} & \multirow{2}{*}{$\begin{array}{c}\text { Adj. } \\
\text { R }\end{array}$} & \multirow{2}{*}{$\mathrm{F}$} & \multirow{2}{*}{ Sig. } \\
\hline & B & Std. Error & & & & Tolerance & VIF & & & & & \\
\hline (Constant) & 2.676 & 0.070 & & 38.201 & 0.000 & & & \multirow{4}{*}{0.658} & \multirow{4}{*}{0.433} & \multirow{4}{*}{0.431} & \multirow{4}{*}{182.549} & \multirow{4}{*}{0.000} \\
\hline Social impact & 0.232 & 0.055 & 0.151 & 4.198 & 0.000 & 0.499 & 2.006 & & & & & \\
\hline Economic impact & 0.873 & 0.056 & 0.480 & 15.582 & 0.000 & 0.722 & 1.384 & & & & & \\
\hline Environmental impact & 0.250 & 0.050 & 0.179 & 4.994 & 0.000 & 0.609 & 1.642 & & & & & \\
\hline
\end{tabular}

Predictors: Social impact, economic impact, and environmental impact; Dependent Variable: The attitude toward the legalization of casino gambling.

$\mathrm{Y}=2.676+0.151 \mathrm{X} 1+0.480 \mathrm{X} 2+0.179 \mathrm{X} 3$

where $\mathrm{y}=$ The attitude toward the legalization of casino gambling

$\mathrm{X} 1=$ Social impact

$\mathrm{X} 2=$ Economic impact

$\mathrm{X} 3=$ Environmental impact

The findings of the multiple regression have a positively significant relationship to social impact $(\beta=0.151$, $\mathrm{t}=4.198, \mathrm{p}<0.05)$, economic impact $(\beta=0.480, \mathrm{t}=$ 15.582, $\mathrm{p}<0.05)$, and environmental impact $(\beta=0.179, \mathrm{t}=$ 4.994, $\mathrm{p}<0.05)$ associated with the legalization of casino gambling. The more positive perceptions in social, economic, and environmental aspects that respondents perceive, the more the respondents showed their willingness to support the legalization of casino gambling.

Thus, as the results of regression models, social impact, economic impact, and environmental are the strongest variables affecting the dependent variables in most of the model, the results of multiple regression partially support and accept Hypothesis 3. At the current level, Taiwanese have different opinions toward the development of the casino tourism business. Supporters emphasize economic development, while the proponents worry about the negative impacts that the casino would bring to society.

\section{Conclusion and Recommendations}

For economic benefits, many local governments have expanded their gambling businesses and in some countries, such as Taiwan and Singapore, are starting their plans to enter this industry. Although there are some successful cases in cities with gambling businesses, such as Las Vegas and Macau, the overall impacts from legalized casinos are still controversial $[24,27,28]$. Proponents worry that the negative impacts on both moral and health grounds, especially in the area of the growing number of issues related to gambling and the possibility of increasing the number of pathological gamblers.

The findings of the three hypotheses are showed as follows:

1) There are significant differences in perceptions toward the legalized casino gambling industry across nongamblers, non-problem gamblers, low-risk gamblers, mo- derate gamblers, and problem gamblers.

2) There are significant differences in attitudes toward the legalized casino gambling industry across non-gamblers, non-problem gamblers, low-risk gamblers, moderate gamblers, and problem gamblers.

3) There are significant relationships between different perceptions toward the legalized casino gambling industry and attitudes toward the legalization of casino gambling.

This study found that social exchange theory could be applied to gaming development, and formulated relationships based on the results of the multiple regression. The formulas show that resident perceptions of social, economic, and environmental aspects could affect their attitudes toward gaming development. The more benefits that residents perceive, the more positive attitudes they show toward gaming developments. The results of the model show the economic impact is the most significant predictor of residents' overall support level; this result is identified with [17] research findings.

\section{Recommendations}

Through the referendum, people who like or are already addicted to gambling are likely to support the legalization, and consequently, problem gambling would become more serious and prevalent. Prior to the opening of any legal casinos in Taiwan, the study could provide some recommendations to the Taiwanese government based on the finding of the questionnaires.

1) Conduct the prevalence study of problem gamblers: As the results show, there have been some gamblers with some risk level and even problem gamblers currently existing in Taiwan. Therefore, it is very important to understand the severity and prevalence of problem gamblers before legalizing casinos. After the establishment of tourism casinos, rules and regulations regarding the proper control and monitoring of problem gamblers must be set up to effectively manage and lower any possible damages.

2) Provide channels to assist problem gamblers: The government should provide some assistance to gamblers who have gambling problems. Currently, there is not much research on problem gamblers in Taiwan. We lack in- 
formation and knowledge about Taiwanese problem gamblers.

3) The referendum results: Many countries around the world have already developed the casino gambling industry, despite research indicating that the prevalence of problem gamblers would increase along with the establishment of casino or gambling machines. If the Taiwan government does not really understand the casino gambling industry and decides to leave the fate of this industry in the hands of the Taiwanese citizens, this might result in a situation in which the country would develop this industry based on demand and not on what the country really needs.

\section{REFERENCES}

[1] J. Henderson, "Betting on Casino Tourism in Asia: Singapore's Integrated Resorts," Tourism Review International, Vol. 10, No. 3, 2006, pp. 169-179.

[2] J. M. Piner and T. W. Paradis, "Beyond the Casino: Sustainable Tourism and Cultural Development on Native American Lands," Tourism Geographies, Vol. 6, No. 1, 2004, pp. 80-98. doi:10.1080/14616680320001722346

[3] T. C. Chang, "Development of Lottery in Taiwan (19002005)," 2009.

http://etds.ncl.edu.tw/theabs/service/detail_result.jsp,2002

[4] M. H. Ho, "Analysis of Framework of Integrated Public Affair and Administration Strategy for Ponghu County's Striving of Subsidiary Gaming Industry in Tourism Special Zone," Unpublished Master's Thesis, National Sun Yat-Sen Unversity, Kaohsiung, 2005.

[5] Y. Ho, "Benefits and Costs of Legalized Gaming in Penghu as Perceived by Taiwanese People," University of Nevada, Reno, 2007.

[6] C. H. C. Hsu, "Casino Industry in Asia Pacific: Development, Operation, and Impact," Haworth Hospitality Press, New York, 2006.

[7] S. J. Zeng, "The Study of Travel \& Tourism Service Failures-The Comparison between Critical Incident Technique (CIT) and Narrative Analysis," 2006.

[8] S. Chen, "The Attitudes of Key Executives of International Tourist Hotels in Taiwan toward Casino Investments in Taiwan," University of Nevada, Reno, 2009.

[9] C. Lee and K. Back, "Examining Structural Relationships among Perceived Impact, Benefit, and Support for Casino Development Based on 4-Year Longitudinal Data," Tourism Management, Vol. 27, No. 3, 2006, pp. 466-480. doi:10.1016/j.tourman.2004.11.009

[10] S. K. Kang, C. Lee, Y. Yoon and P. T. Long, "Resident Perception of the Impact of Limited-Stakes CommunityBased Casino Gaming in Mature Gaming Communities," Tourism Management, Vol. 29, No. 4, 2008, pp. 681-694. doi:10.1016/j.tourman.2007.07.011

[11] G. Reith, "Research on the Social Impacts of Gambling," Scottish Executive Social Research, 2006.

[12] F. Vong, "Influence of Personal Factors on Macau Residents' Gaming Impact Perceptions," UNLV Gaming Re- search \& Review Journal, Vol. 12, No. 1, 2008, pp. 1528.

[13] F. Vong, “Changes in Residents' Gambling Attitudes and Perceived Impacts at the Fifth Anniversary of Macao's Gaming Deregulation," Journal of Travel Research, Vol. 47, No. 3, 2009, pp. 388-397. doi: $10.1177 / 0047287508322787$

[14] M. W. Abbott, R. A. Volberg and S. Rönnberg, "Comparing the New Zealand and Swedish National Surveys of Gambling and Problem Gambling," Journal of Gambling Studies, Vol. 20, No. 3, 2004, pp. 237-258. doi:10.1023/B:JOGS.0000040278.08853.c0

[15] M. W. Abbott and R. A. Volberg, "The New Zealand National Survey of Problem and Pathological Gambling," Journal of Gambling Studies, Vol. 12, No. 2, 1996, pp. 143-160.

[16] D. K.-C. Fong and B. Ozorio, "Gambling Participation and Prevalence Estimates of Pathological Gambling in a Far-East Gambling City: Macao," UNLV Gaming Research \& Review Journal, Vol. 9, No. 2, 2005, pp. 15-28.

[17] C. Blume, "Survey Says Asia's Gaming Revenue Likely to Surpass That of US by 2012," 2008. http://NewsVOAcom

[18] Z. Gu and J. Z. Gao, "Financial Competitiveness of Macau in Comparison with Other Gaming Destinations," UNLV Gaming Research \& Review Journal, Vol. 10, No. 2, 2006, pp. 1-12.

[19] S. Kang and C. H. C. Hsu, "Outlook in the 21st Century," Department of Hotel Restaurant Institution, Vol. 21, No. 2, 2000, pp. 15-17.

[20] W. S. Wu, "Flower Match Games in Taiwan," The Journal of History, Vol. 1, 1988, pp. 62-64.

[21] C. F. Shiu, "A Study on Public-Interest Lottery in Taiwan, 2005," 2009. http://etds.ncl.edu.tw/theabs/service/detail_result.jsp

[22] T. P. S. Oei and L. M. Gordon, "Psychosocial Factors Related to Gambling Abstinence and Relapse in Members of Gamblers Anonymous," Journal of Gambling Studies, Vol. 24, No. 1, 2008, pp. 91-105. doi:10.1007/s10899-007-9071-7

[23] D. A. Abbott and S. L. Cramer, "Gambling Attitudes and Participation: A Midwestern Survey," Journal of Gambling Studies, Vol. 9, No. 3, 1993, p. 247. doi:10.1007/BF01015921

[24] D. Chhabra and D. Gursoy, "Perceived Impacts of Gambling: Integration of Two Theories," UNLV Gaming Research \& Review Journal, Vol. 11, No. 1, 2007, pp. $27-$ 40.

[25] W. S. Roehl, "Quality of Life Issues in a Casino Destination," Journal of Business Research, Vol. 44, No. 3, 1999 , pp. 223-229. doi:10.1016/S0148-2963(97)00203-8

[26] J. Hua, "The Research for Social Policy Lottery-For Example, That Made by Taipei Bank," 2004.

[27] A. Pizam and P. Pokela, "Perceived Impacts of Casino Gambling on a Community," Annals of Tourism Research, Vol. 12, No. 1, 1985, p. 147. doi:10.1016/0160-7383(85)90054-4 
[28] B. G. Stitt, M. Nichols and D. Giacopassi, "Perceptions of the Extent of Problem Gambling within New Casino Com- munities," Journal of Gambling Studies, Vol. 16, No. 4 2000, pp. 433-451. doi:10.1023/A:1009436324278 